\title{
Dynamic Reference-based Voltage Droop Control for VSC-MTDC System
}

\author{
Nam-Dae Kim*, Hak-Man Kim** and Jae-Sae Park ${ }^{\dagger}$
}

\begin{abstract}
The use of voltage source converter multi-terminal direct current (VSC-MTDC) systems is anticipated to increase from the introduction of wind farms and super grids in the near future. Effective control of the DC voltage in VSC-MTDC systems is an important research topic. This paper proposes a new dynamic reference-based voltage droop control to control the DC voltage in VSCMTDC systems more effectively. The main merit of the dynamic reference-based voltage droop control is that it can reduce the steady-state error in conventional voltage droop control by changing references according to the system operating conditions. The performance of the proposed control was tested in a hardware-in-the-loop simulation (HILS) system based on the OPAL-RT real-time digital simulator and four digital signal processing boards.
\end{abstract}

Keywords: Multi-terminal VSC-MTDC, Hardware-in-the-loop simulation (HILS), HILS system based on OPAL-RT RTDS, Dynamic reference-based voltage droop control

\section{Introduction}

The fast growth of wind farms and super grids has led to rising interest in multi-terminal direct current (MTDC) systems. Recent advances in modular multi-level converters (MMCs) have led to increased research on voltage source converter MTDC (VSC-MTDC) applications [1-3]. In particular, DC voltage control schemes such as voltage margin control and voltage droop control are being developed to realize stable and effective control for the DC voltage of an MTDC system [4-7].

In voltage margin control, a converter controls the DC voltage of a VSC-MTDC in the normal state as a regulator. When the DC voltage rises or drops from mismatches between the power supply and power demand, other converters supply or receive power according to DC voltage references to maintain the DC voltage within the operating range. However, one drawback is the slow dynamic response of the control scheme [8-12].

In voltage droop control, all converters have the same control role of controlling the DC voltage by the droop function. Thus, this control has a simpler structure than voltage margin control. However, its drawback is the steady-state error that occurs in general droop control applications [13-17].

This paper proposes a new dynamic reference-based voltage droop control that improves upon the conventional voltage droop control by reducing the steady-state error

$\dagger$ Corresponding Author: Dept. of Electrical Engineering, Incheon National Univ., Korea. (js8700@inu.ac.kr)

* Korea Electric Power Corporation Research Institute (KEPRI), Korea. (namdae88@kepco.co.kr)

** Dept. of Electrical Engineering, Incheon National Univ., Korea. (hmkim@inu.ac.kr)

Received: February 21, 2015; Accepted: August 12, 2015 while maintaining a simple structure. In Section 3, the principle of the control is described in detail. To demonstrate the performance of the control in the laboratory, a hardware-in-the-loop simulation (HILS) system was developed. The HILS system was composed of four digital signal processing (DSP) boards for implementing the proposed control in the four converters of a four-terminal VSC-MTDC system as an embedded system and the OPAL-RT real-time digital simulator (RTDS) for real-time modeling and simulation of the rest of the four-terminal VSC-MTDC system. The performance of the proposed control was compared with the performances of voltage margin control and voltage droop control in the HILS system.

\section{Conventional Control Schemes}

\subsection{Voltage margin control}

Eq. (1) expresses the voltage margin in voltage margin control for stable control of the DC voltage of a VSCMTDC system. When the DC voltage of the VSC-MTDC system is maintained within the voltage margin, the controller of a converter controls the DC voltage as a voltage regulator, and the controllers of other converters keep the real power constant based on references. Eq. (2) expresses the current reference determined according to the system voltage, and Fig. 1 shows the voltage margin controller based on Eq. (2) $[18,19]$.

$$
V_{\text {margin }}=V_{d c, \text { ref }}^{\text {high }}-V_{d c, \text { ref }}^{\text {low }}
$$

where $V_{\text {margin }}$ is the voltage margin, $V_{d c, \text { ref }}^{\text {high }}$ is the upper 


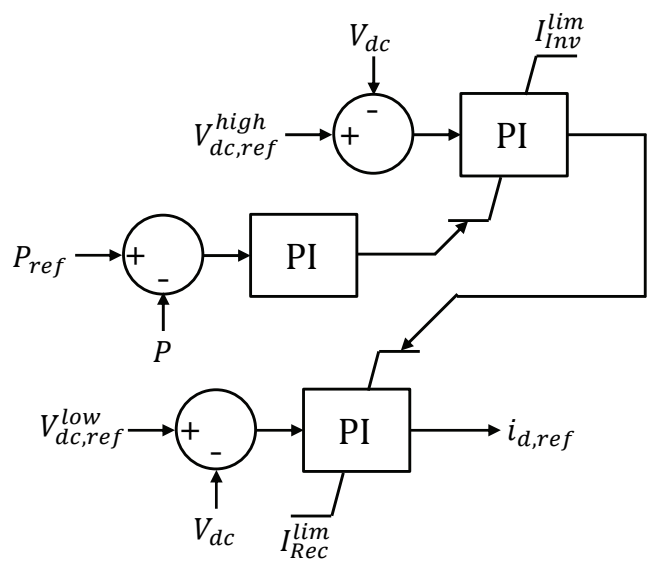

Fig. 1. Block diagram of voltage margin control.

limit of the DC voltage reference, and $V_{d c, \text { ref }}^{\text {low }}$ is the lower limit of the DC voltage reference.

$$
i_{d, r e f}=\left\{\begin{array}{c}
\left(V_{d c, r e f}^{\text {high }}-V_{d c}\right)\left[k_{P}+\frac{k_{I}}{s}\right] \text { If } V_{d c} \geq V_{d c, r e f}^{\text {high }} \\
\left(V_{d c, r e f}^{\text {low }}-V_{d c}\right)\left[k_{P}+\frac{k_{I}}{s}\right] \text { If } V_{d c} \leq V_{d c, r e f}^{\text {low }} \\
\left(P_{r e f}-P\right)\left[k_{P}+\frac{k_{I}}{s}\right] \text { If } V_{d c, r e f}^{\text {low }}<V_{d c}<V_{d c, r e f}^{\text {high }}
\end{array}\right.
$$

where $P_{r e f}$ is the reference of the real power, and $i_{d, r e f}$ is the reference of the converter current on the d-axis.

The voltage margin control has a slow dynamic response because of its control structure; as a drawback, a relatively large voltage margin is needed to avoid interactions between converters $[18,19]$.

\subsection{Voltage droop control}

In voltage droop control, stable control of the DC voltage is realized by determining the real power output of converters in the VSC-MTDC according to the change in voltage. The droop gain is defined by the relation between the real power output of converters and the DC voltage limits as determined by the VSC-MTDC condition given in Eq. (3):

$$
\rho=\frac{V_{d c}^{\max }-V_{d c}^{\min }}{P_{R e c}^{\lim }-P_{I n v}^{\lim }}
$$

where $\rho$ is the droop gain, $V_{d c}^{\max }$ is the maximal value of the DC voltage, $V_{d c}^{\min }$ is the minimal value of the DC voltage, $P_{R e c}^{\lim }$ is the limit of a converter working as a rectifier, and $P_{I n v}^{l i m}$ is the limit of a converter working as a inverter.

Fig. 2 shows a block diagram of voltage droop control based on Eqs. (4) and (5) [20, 21].

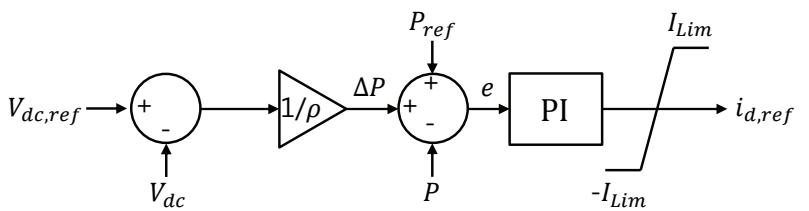

Fig. 2. Block diagram of voltage droop control.

$$
\begin{gathered}
e=P_{r e f}-P+\frac{\left(V_{d c, r e f}-V_{d c}\right)}{\rho}=0 \\
V_{d c}=V_{d c, r e f}+\rho\left(P_{r e f}-P\right)
\end{gathered}
$$

where $V_{d c, \text { ref }}$ is the reference DC voltage.

In voltage droop control, the advantage is that the DC voltage can be controlled by multiple converters without a communication link. However, the drawback of voltage droop control is the steady-state error.

\section{Proposed Dynamic Reference-based Voltage Droop Control}

This paper proposes a new DC voltage droop controller based on dynamic references that reduces the steady-state error of conventional voltage droop control by changing the references for the voltage droop control according to the VSC-MTDC condition. It is called dynamic referencebased voltage droop control. The principle of the proposed control is shown in Figs. 3 and 4. When the DC voltage is

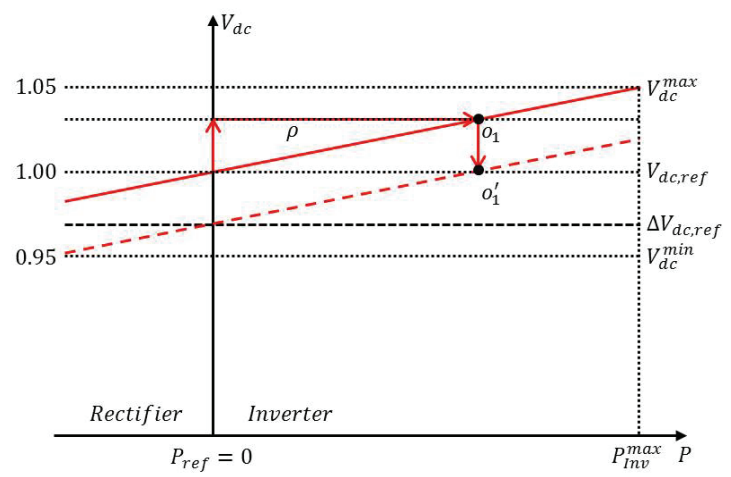

Fig. 3. $P-V_{d c}$ curve when voltage is increasing.

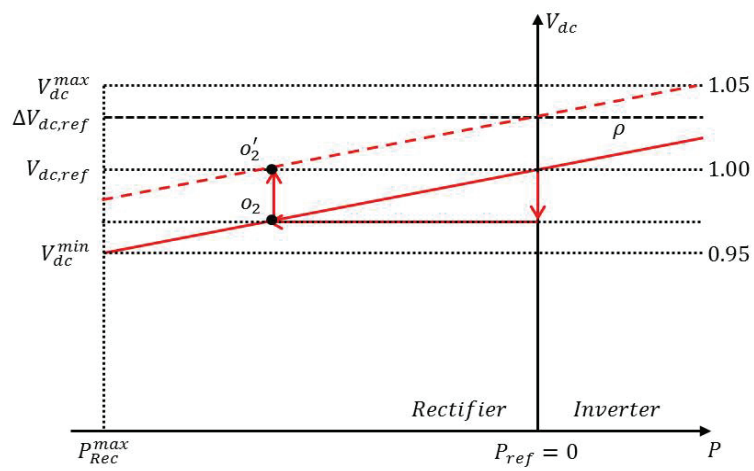

Fig. 4. $P-V_{d c}$ curve when voltage is decreasing. 


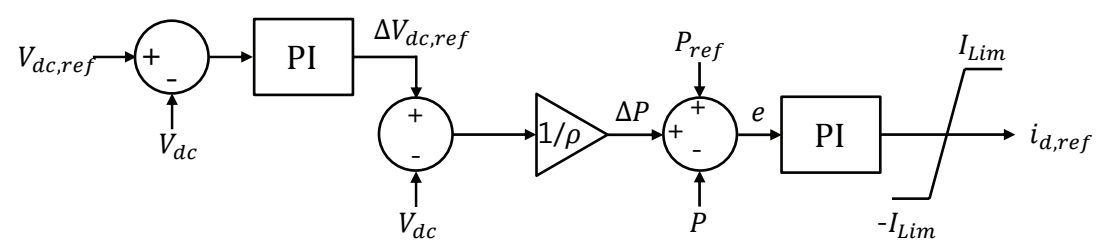

Fig. 5. Block diagram of dynamic reference-based voltage droop control.

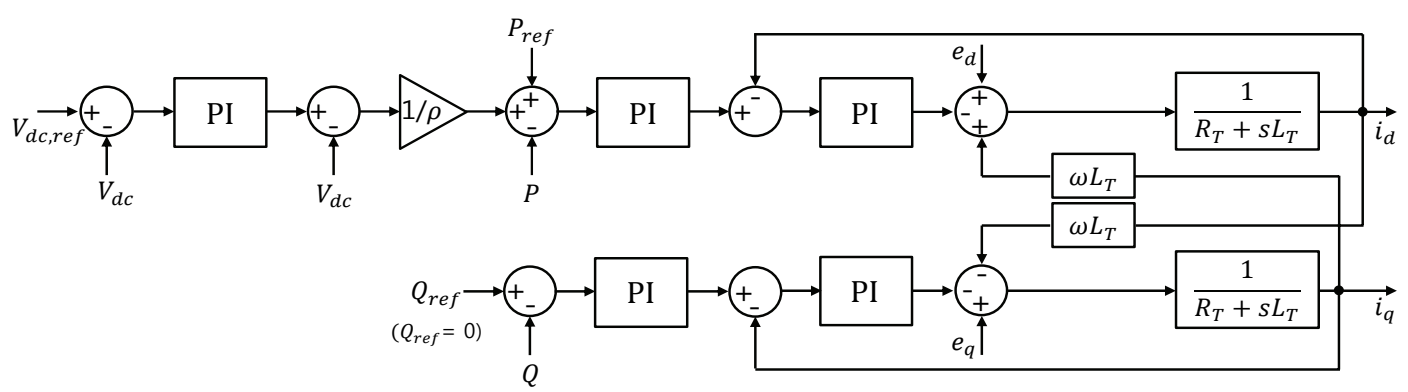

Fig. 6. Block diagram of control system of VSC-HVDC with current control.

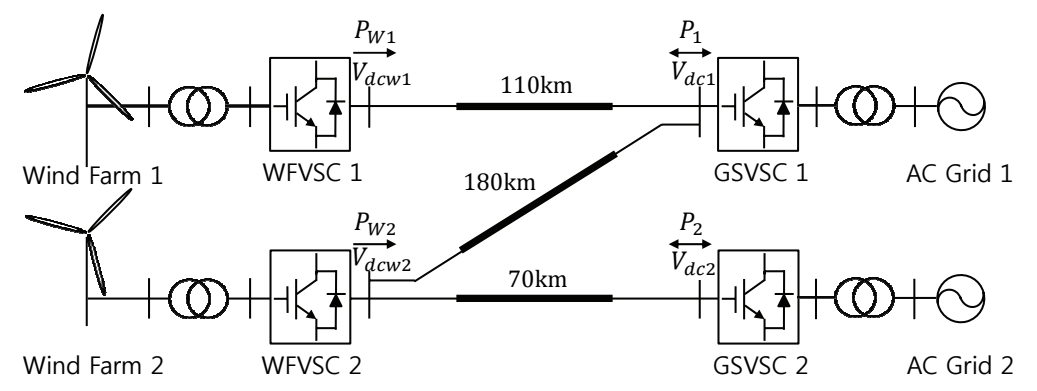

Fig. 7. Layout of four-terminal VSC-MTDC system with wind farms and AC grids.

increasing, it reaches point $\mathrm{O}_{1}$ shown in Fig. 4 and produces a steady-state error. To reduce this error, the proposed control intentionally changes the reference of the DC voltage to point $\mathrm{O}_{1}^{\prime}$. When the $\mathrm{DC}$ voltage is decreasing, it reaches point $\mathrm{O}_{2}$ shown in Fig. 5 and produces a steady-state error. To reduce this error, the proposed control intentionally changes the reference of the DC voltage to point $\mathrm{O}_{2}^{\prime}$.

Fig. 5 shows a block diagram of the dynamic referencebased voltage droop control. Fig. 6 shows a block diagram of the control system of a VSC-HVDC with current control. The dynamic reference to reduce the steady-state error of the voltage droop control can be obtained by Eqs. (6) and (7).

$$
\begin{gathered}
\Delta V_{d c, r e f}=\left(V_{d c, r e f}-V_{d c}\right)\left[k_{P}+\frac{k_{I}}{s}\right] \\
\Delta P=\frac{\Delta V_{d c, r e f}-V_{d c}}{\rho}
\end{gathered}
$$

where $V_{d c}$ is the DC voltage and $\Delta V_{d c, r e f}$ is the dynamic reference.

\section{Hardware-in-the Loop Simulation System for Testing Performance of DC Voltage Controller}

Fig. 7 shows the test four-terminal VSC-MTDC system with wind farms and $\mathrm{AC}$ grids, which was used to test the performance of the proposed dynamic reference-based voltage droop control. Table 1 lists the parameters of the system $[22,23]$.

Fig. 8 shows the configuration of the developed HILS system. The 4-terminal VSC-MTDC system was modeled in the OPAL-RT RTDS. The conventional control schemes and the proposed control scheme were implemented in 4 DSP boards. The DSP boards receives measured voltage and current information from the OPAL-RT RTDS and

Table 1. Parameters of four-terminal VSC-MTDC system.

\begin{tabular}{c|c|c|c}
\hline AC Grid & $3500 \mathrm{MVA}$ & VSC Freq. & $2.5 \mathrm{kHz}$ \\
\hline AC Voltage & $220 / 180 \mathrm{kV}$ & DC Capacitor & $75 \mu \mathrm{F}$ \\
\hline WFVSC 1 & $400 \mathrm{MVA}$ & DC Voltage & $400 \mathrm{kV}$ \\
\hline WFVSC 2 & $400 \mathrm{MVA}$ & Cable $\mathrm{R} / \mathrm{km}$ & $0.015 \Omega$ \\
\hline GSVSC 1 & $500 \mathrm{MVA}$ & Cable $\mathrm{L} / \mathrm{km}$ & $0.792 \mathrm{mH}$ \\
\hline GSVSC 2 & $400 \mathrm{MVA}$ & Cable $\mathrm{C} / \mathrm{km}$ & $14.4 \mathrm{nF}$ \\
\hline
\end{tabular}




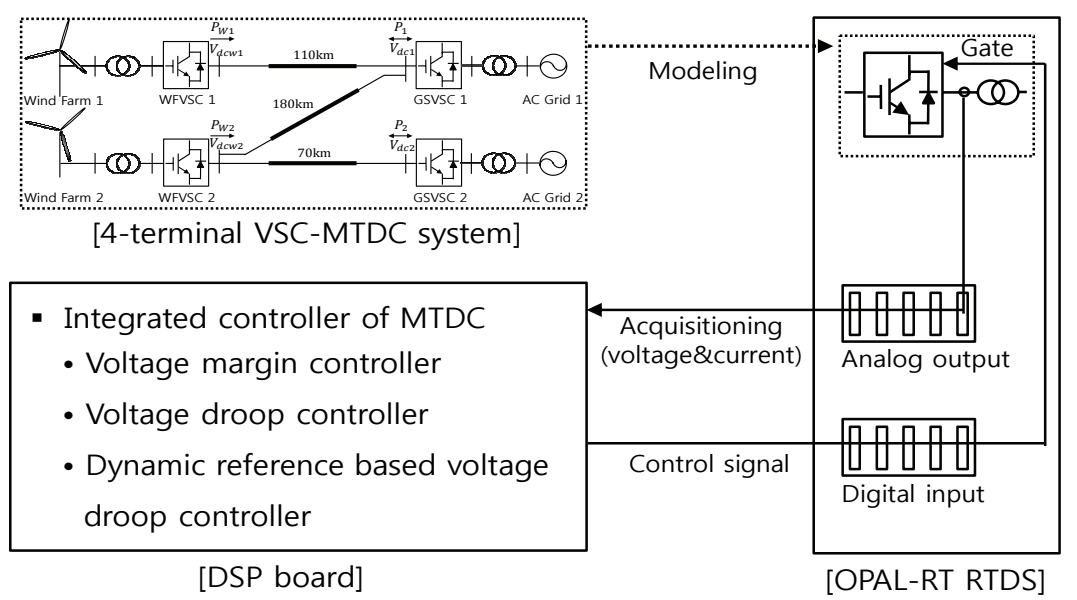

Fig. 8. Configuration of HILS system.

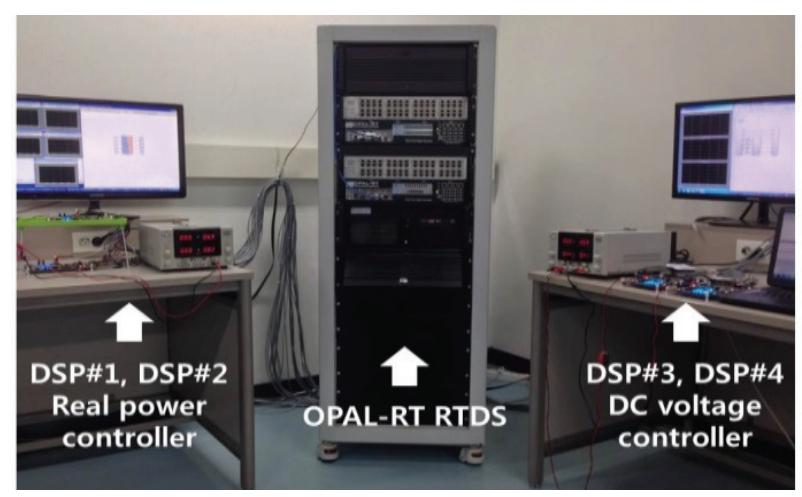

Fig. 9. HILS system developed in the laboratory.

sends PWM signals to IGBT gates of four VSCs in the OPAL-RT RTDS by real-time.

Fig. 9 shows the developed HILS system, which was based on four DSP boards as controllers of four VSCs and OPAL-RT RTDS as a real-time digital simulator to test the performance of the proposed control. In the HILS system, DSP boards 1 and 2 control the real power of WFVSC 1 and WFVSC 2, and DSP boards 3 and 4 control the DC voltage using GSVSC 1 and GSVSC 2. The rest of the four-terminal VSC-MTDC system was modeled with the real-time simulation software RT-LAB. The four DSP boards and OPAL-RT RTDS exchange digital and analog data by real-time communication. Voltage margin control and conventional voltage droop control were implemented with the four DSP boards to compare the control performances of the different schemes.

\section{Test Results}

In order to evaluate the performance of the dynamic reference-based voltage droop control in the HILS system, two operation conditions (Cases 1 and 2) were applied to the four-terminal VSC-MTDC system shown in Fig. 7. Permanent three-phase ground faults were applied near the wind farm 1 side at $0.5 \mathrm{~s}$ (Case 1) and near the AC side of GSVSC 1 (Case 2). For the initial conditions of the two cases, WFVSC 1 transferred a real power of $0.2 \mathrm{pu}$, and WFVSC 2 transferred a real power of $0.4 \mathrm{pu}$, GSVSC 1 and GSVSC 2 were used for the proposed control scheme.

\subsection{Case 1}

Fig. 10 shows the real power transferred from each converter by the dynamic reference-based voltage droop controller when the fault occurred near the wind farm 1 side at $0.5 \mathrm{~s}$. $\mathrm{P}_{1}$ and $\mathrm{P}_{2}$ represent the real power outputs of GSVSC 1 and GSVSC 2, respectively, and $\mathrm{P}_{\mathrm{W} 1}$ and $\mathrm{P}_{\mathrm{W} 2}$ represent the real power outputs of WFVSC 1 and WFVSC 2 , respectively. $\mathrm{P}_{1}$ and $\mathrm{P}_{2}$ were changed simultaneously by the droop gain. However, $\mathrm{P}_{\mathrm{W} 1}$ dropped to zero because of the permanent fault at $0.5 \mathrm{~s}$. GSVSC 1 and GSVSC 2 decreased $\mathrm{P}_{\mathrm{W} 1}$ and $\mathrm{P}_{\mathrm{W} 2}$ to compensate for $\mathrm{P}_{\mathrm{W} 1}$, which was decreased to zero from WFVSC 1. Fig. 11 shows that the DC voltages in the four converters were stably controlled during the fault. The results show that the Vdc1 and Vdc2 of two converters, GSVSC 1 and GSVSC 2, controlled by the proposed control scheme were controlled well without a steady-state error as designed.

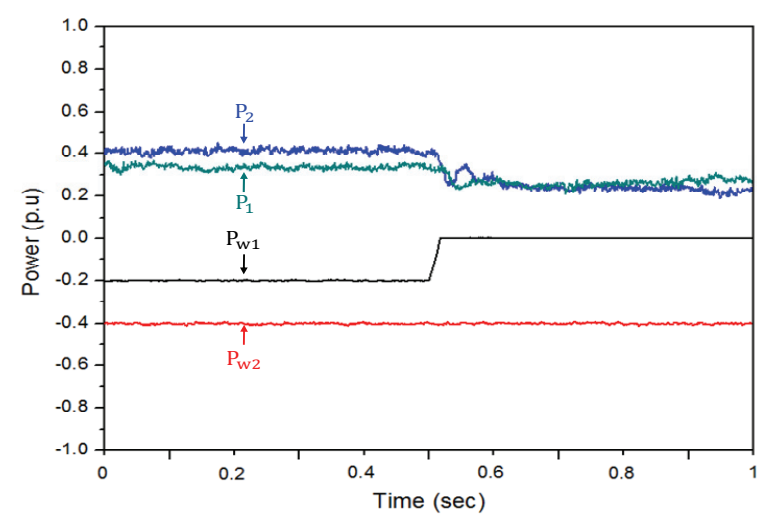

Fig. 10. Real power transferred from converters (Case 1). 


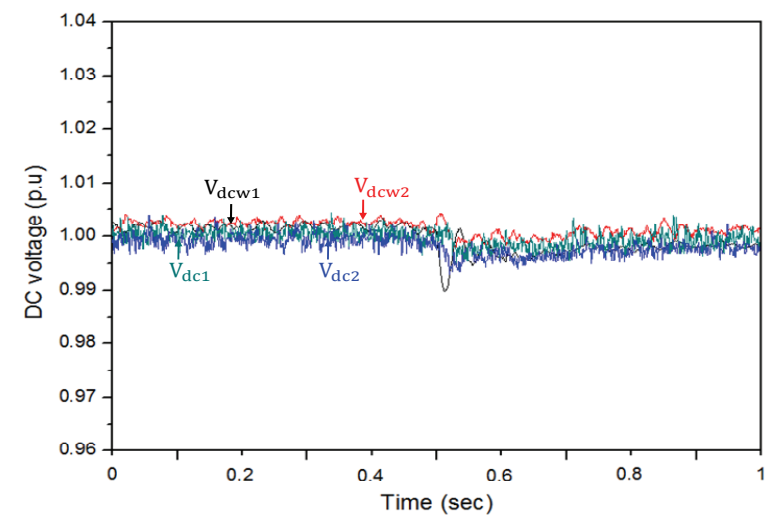

Fig. 11. DC voltages (Case 1).

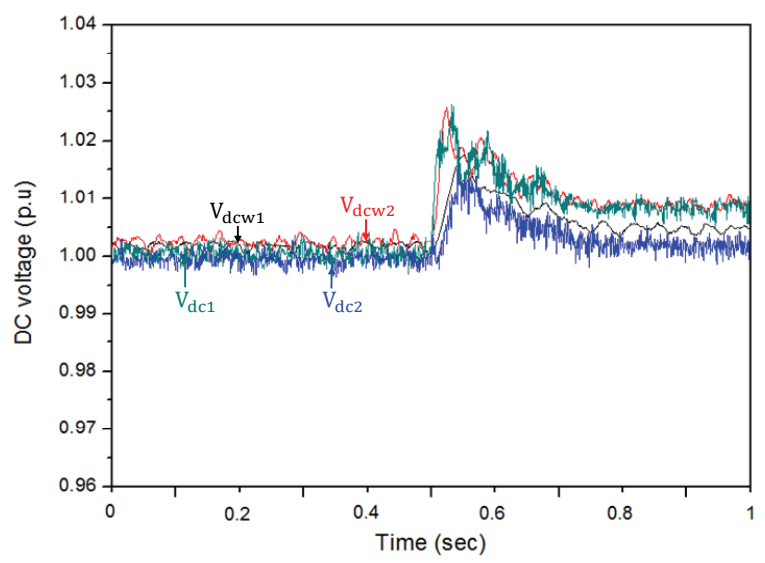

Fig. 13. DC voltages (Case 2).

\subsection{Case 2}

Fig. 12 shows the real power transferred from each converter by the dynamic reference-based voltage droop controller when a fault occurred near the $\mathrm{AC}$ side of GSVSC 1 at 0.5 s. $\mathrm{P}_{\mathrm{W} 1}$ and $\mathrm{P}_{\mathrm{W} 2}$ were continuously maintained during the fault. Because the $\mathrm{P}_{1}$ transferred from GSVSC 1 was dropped to zero by the fault, GSVSC 2 increased $\mathrm{P}_{2}$ to compensate for the real power shortage to control the DC voltage. Fig. 13 shows that the DC voltage was controlled stably during the fault. The results show that the $\operatorname{Vdc} 2$ of GSVSC 2 controlled by the proposed control scheme was controlled well without a steadystate error as designed. However, Vdc1 was not controlled because the AC fault was applying to the AC side of GSVSC 1 was applied.

\subsection{Performance comparison of controllers}

Fig. 14 shows the DC voltages with each control when the fault occurred near the wind farm 1 side at $0.5 \mathrm{~s}$ (Case 1) to compare control performances. The results show that the voltage droop control controlled the DC voltage to 1.01 pu, which implies a steady-state error of $0.01 \mathrm{pu}$. However, the voltage margin control and proposed dynamic reference-

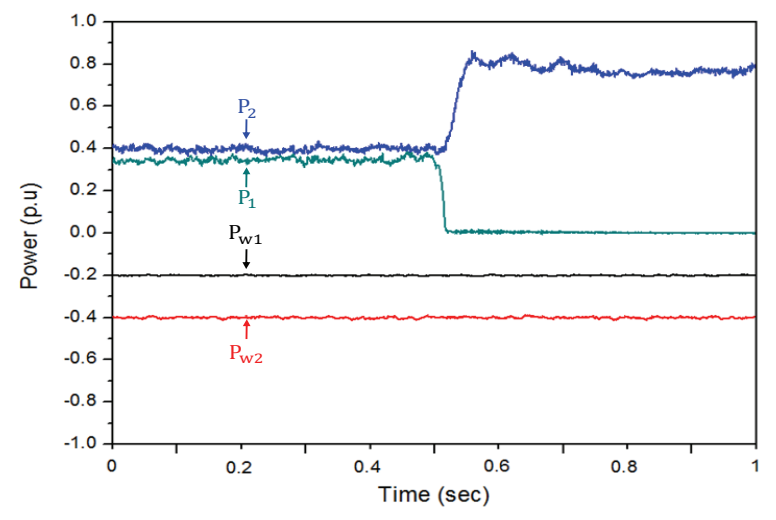

Fig. 12. Real power transferred from converters (Case 2).

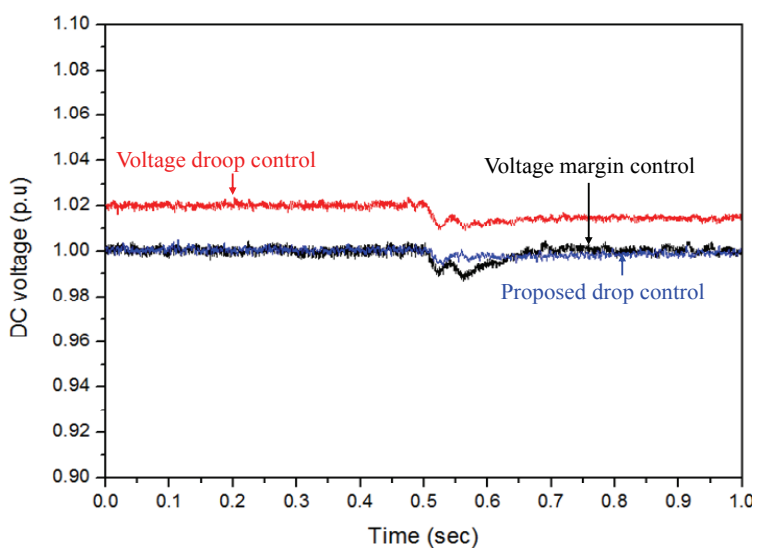

Fig. 14. Performance comparison (Case 1).

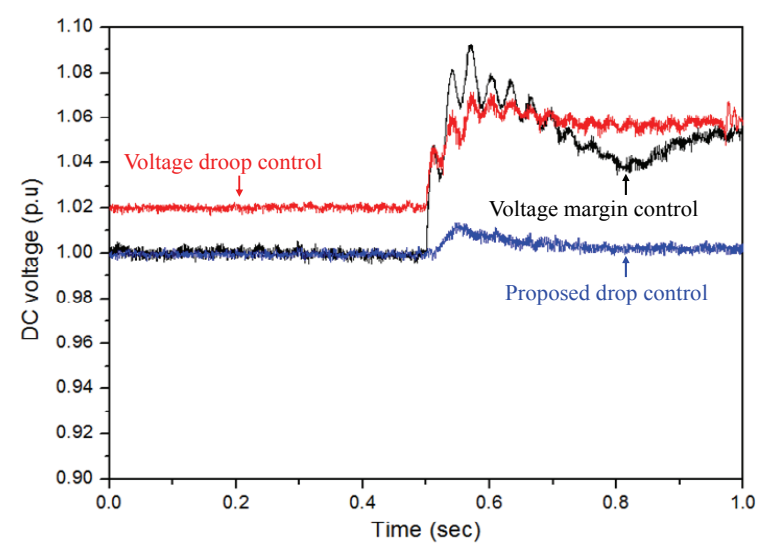

Fig. 15. Performance comparison (Case 2).

based voltage droop control controlled the DC voltages to $1.0 \mathrm{pu}$, so there was no steady-state error.

Fig. 15 shows the DC voltages with each control when the fault occurred near the AC side of GSVSC 1 at $0.5 \mathrm{~s}$ (Case 2) to compare control performances. The DC voltages with the voltage margin control and voltage droop control were controlled to $1.045 \mathrm{pu}$ and $1.038 \mathrm{pu}$, respectively. These results show that both controls produced a steadystate error. However, the DC voltage with the proposed dynamic reference-based voltage droop control was 
Table 2. Performance comparison of controls.

\begin{tabular}{c|c|c}
\hline Controller & Case 1 & Case 2 \\
\hline Voltage margin & $1.0 \mathrm{pu}$ & $1.045 \mathrm{pu}$ \\
\hline Voltage droop & $1.016 \rightarrow 1.01 \mathrm{pu}$ & $1.016 \rightarrow 1.038 \mathrm{pu}$ \\
\hline $\begin{array}{c}\text { Dynamic reference based } \\
\text { voltage droop }\end{array}$ & $1.0 \mathrm{pu}$ & $1.0 \mathrm{pu}$ \\
\hline Controller & Case 1 & Case 2 \\
\hline
\end{tabular}

controlled to almost $1.0 \mathrm{pu}$. This means that the proposed control can reduce the steady-state error relatively well.

Table 2 summarizes the performance test results. The proposed control provided the best performance because it produced new control references to reduce the steady-state errors depending on the operating conditions.

\section{Conclusion}

This paper proposed a new dynamic reference-based voltage droop controller to control the DC voltage in a VSC-MTDC system. The performance of the controller was tested using a developed HILS system and compared against voltage margin control and voltage droop control. In the results, the proposed controller showed the best performance because it can produce control references dynamically to reduce the steady-state error.

\section{Acknowledgment}

This work was supported by an Incheon National University Research Grant awarded in 2012.

\section{References}

[1] M. Bames and A. Beddard, "Voltage source converter HVDC links-The state of the art and issues going forward," Journal of Energy Procedia, vol. 24, pp. 108-122, Jan. 2012.

[2] Jiebei Zhu and C. Booth, "Future multi-terminal HVDC transmission systems using Voltage source converters," in Proc. Universities Power Engineering Conference (UPFC), pp. 1-6, Aug. 2010.

[3] S. Taggart, G. James, Dong Zhaoyang, and C. Russell, "The Future of Renewables Linked by a Transnational Asian Grid," in Proc. IEEE, vol. 100, no. 2, pp. 348-359, Feb. 2012.

[4] Ling $\mathrm{Xu}$ and Lingling Fan, "System identification based VSC-HVDC DC voltage controller design," in Proc. North American Power Symposium (NAPS), pp. 1-6, Sept. 2012.

[5] Dirk Van Hertem and Mehrdad Ghandhari, "Multiterminal VSC HVDC for the European supergrid: Obstacles," Journal of Renewable and Sustainable Energy Reviews, vol. 14, pp. 3156-3163, Dec. 2010.
[6] T. M. Haileselassie, "Control, Dynamics and Operation of Multi-terminal VSC-HVDC Transmission Systems," Ph. D. Thesis, Norwegian University of Science and Technology, Norway, 2012.

[7] T. M. Haileselassie and K. Uhlen, "Precise Control of Power Flow in Multiterminal VSC-HVDCs Using DC Voltage Droop Control," in Proc. Power and Energy Society General Meeting, pp. 1-9, July 2012.

[8] T. Nakajima, Irokawa, and Shoichi, "A control system for HVDC transmission by voltage sourced converters," in Proc. Power Engineering Sociert Summer Meeting, vol. 2, pp. 1113-1119, July 1999.

[9] R. T. Pinto, S. F. Rodrigues, P. Bauer, and J. Pierik, "Comparison of direct voltage control methods of multi-terminal DC (MTDC) networks through modular dynamic models," in Proc. 14th European Conference, pp. 1-10, Aug. 2011.

[10] C. Dierckxsens, K. Srivastava, M. Reza, S. Cole, J. Beerten, and R. Belmans, "A distributed DC voltage control method for VSC MTDC systems," Journal of Electric Power Systems Research, vol. 82, pp. 54-58, 2012.

[11] F. Gonzalez-Longatt and J. M. Roldan, "Effects of dc voltage control strategies of voltage response on multi-terminal HVDC following a disturbance," in Proc. Universities Power Engineering Conference (UPFC), pp. 1-6, Sept. 2012.

[12] S. F. Rodrigues, R. Teixeira Pinto, and P. Bauer, Dynamic Modeling and Control of VSC-based Multiterminal DC Networks, Lambert Academic, 2012

[13] B. K. Johnsin, R. H. Lasseter, F. L. Alvarado, and R. Adapa, "Expandable multiterminal DC systems based on voltage droop," IEEE Trans. on Power Delivery, vol. 8, no. 4, pp. 1926-1932, Oct. 1993.

[14] Ke Wang, Jianguo Yao, Jiantao Liu, Shengchun Yang, and Dan Zeng, "A generalized power control strategy with droop feedback for VSC-HVDC," in Proc. Power and Energy Society General Meeting, pp. 1-6, July 2012.

[15] J. Beerten, S. Cole, and R. Belmans, "Modeling of Multi-Terminal VSC HVDC Systems With Distributed DC Voltage Control," IEEE Trans. on Power Systems, vol. 29, no. 1, Jan. 2014.

[16] T. M. Haileselassie and K. Uhlen, "Impact of DC Line Voltage Drops on Power Flow of MTDC Using Droop Control," IEEE Trans. on Power Systems, vol. 27, no. 3, pp. 1441-1449, Aug. 2012.

[17] L. Xu, L. Yao, and M. Bazargan, "DC grid management of a multi-terminal HVDC transmission system for large offshore wind farms," in Proc. Sustainable Power Generation and Supply, pp. 1-7, Apr. 2009.

[18] C. Ismunandar, "Control of Multi-Terminal VSCHVDC for Offshore Wind Power Integration," Master Thesis, Delft University of Technology, Netherlands, 2009.

[19] R. T. Pinto, "Multi-Terminal DC Networks System 
Integration, Dynamics and Control," Ph. D. Thesis, Delft University of Technology, Netherlands, 2014.

[20] M. B. Uria, "Operation and Control of Multi-Terminal DC (MTDC) Grids," Master Thesis, Aalborg University, Denmark, 2013.

[21] G. P. Adam, S. J. Finney, B. W. Williams, K. Bell, and G. M. Burt, "Control of multi-terminal DC transmission system based on voltage source converters," in Proc. 9th IET International Conference, pp. 1-5, Oct. 2010.

[22] W. Wenyuan and M. Barnes, "Power Flow Algorithms for Multi-Terminal VSC-HVDC With Droop Control," IEEE Trans. on Power Systems, vol. 29, no. 4, pp. 1721-1730, July. 2014.

[23] R. T. Pinto, "Multi-Terminal DC Networks System Integration, Dynamics and Control," Ph. D. Thesis, Delft University of Technology, Netherlands, 2014.

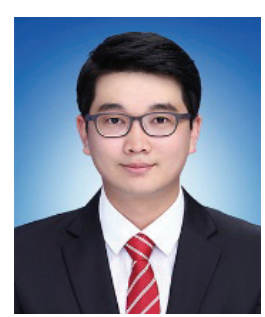

Nam-Dae Kim received his B.S and M.S degrees in Electrical Engineering from In-cheon National University, Korea, in 2013 and 2015, respectively. He joined KEPRI's Power Transmission Lab. as a researcher in June 2015. Currently, His research interests include power system control and substation automation based on IEC 61850 .

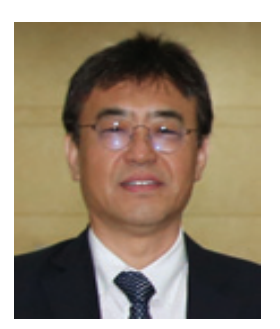

Hak-Man Kim received his first Ph. D. degree in Electrical Engineering from Sungkyunkwan University, Korea, in 1998 and received his second Ph. D. degree in Information Sciences from Tohoku University, Japan, in 2011, respectively. He worked for Korea Electrotechnology Research Institute (KERI), Korea from Oct. 1996 to Feb. 2008. Currently, he is a professor in the Department of Electrical Engineering, Incheon National University, Korea. His research interests include DC power systems, FACTS, and microgrid. Prof. Kim is a Senior Member of IEEE and a Senior Member of KIEE.

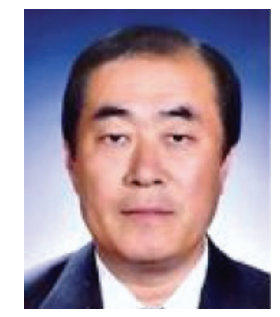

Jae-Sae Park received his Ph.D degree in Electrical Engineering from Sungkyunkwan University, Korea, in 2004. Currently, he is a professor in the Department of Electrical Engineering, Incheon National University, Korea. His research interests include power system modeling and power facility design. 